\title{
Loss of MTUS1/ATIP expression is associated with adverse outcome in advanced bladder carcinomas: data from a retrospective study
}

\author{
Anja Rogler', Sabine Hoja ${ }^{1}$, Johannes Giedl', Arif B Ekici², Sven Wach³, Helge Taubert ${ }^{3}$, Peter J Goebell',
} Bernd Wullich ${ }^{3}$, Michael Stöckle ${ }^{4}$, Jan Lehmann ${ }^{5}$, Sabrina Petsch ${ }^{6}$, Arndt Hartmann ${ }^{1}$ and Robert Stoehr ${ }^{1 *}$

\begin{abstract}
Background: Seventy percent of all bladder tumours tend to recur and need intensive surveillance, and a subset of tumours progress to muscle-invasive and metastatic disease. However, it is still difficult to find the adequate treatment for every individual patient as it is a very heterogeneous disease and reliable biomarkers are still missing. In our study we searched for new target genes in the critical chromosomal region $8 p$ and investigated the potential tumour suppressor gene candidate MTUSI/ATIP in bladder cancer.

Methods: MTUS1 was identified to be the most promising deleted target gene at 8p in aCGH analysis with 19 papillary bladder tumours. A correlation with bladder cancer was further validated using immunohistochemistry of 85 papillary and 236 advanced bladder tumours and in functional experiments. Kaplan-Meier analysis and multivariate Cox-regression addressed overall survival (OS) and disease-specific survival (DSS) as a function of MTUS1/ATIP expression. Bivariate correlations investigated associations between MTUS1/ATIP expression, patient characteristics and histopathology. MTUS1 expression was analysed in cell lines and overexpressed in RT112, where impact on viability, proliferation and migration was measured.

Results: MTUS1 protein expression was lost in almost 50\% of all papillary and advanced bladder cancers. Survival, however, was only influenced in advanced carcinomas, where loss of MTUS1 was associated with adverse OS and DSS. In this cohort, there was also a significant correlation of MTUS1 expression and histological subtype: positive expression was detected in all micropapillary tumours and aberrant nuclear staining was detected in a subset of plasmocytoid urothelial carcinomas. MTUS1 was expressed in all investigated bladder cell lines and overexpression in RT112 led to significantly decreased viability.

Conclusions: MTUS1 is a tumour suppressor gene in cultured bladder cancer cells and in advanced bladder tumours. It might represent one new target gene at chromosome 8p and can be used as an independent prognostic factor for advanced bladder cancer patients. The limitation of the study is the retrospective data analysis. Thus, findings should be validated with a prospective advanced bladder tumour cohort.
\end{abstract}

Keywords: MTUS1, ATIP, Bladder cancer, Chromosome 8p deletions

\footnotetext{
* Correspondence: Robert.stoehr@uk-erlangen.de

${ }^{1}$ Institute of Pathology, University Hospital Erlangen, Krankenhausstr. 8-10,

91054 Erlangen, Germany

Full list of author information is available at the end of the article
}

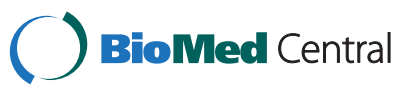

(c) 2014 Rogler et al.; licensee BioMed Central Ltd. This is an Open Access article distributed under the terms of the Creative Commons Attribution License (http://creativecommons.org/licenses/by/2.0), which permits unrestricted use, distribution, and reproduction in any medium, provided the original work is properly credited. The Creative Commons Public Domain Dedication waiver (http://creativecommons.org/publicdomain/zero/1.0/) applies to the data made available in this article, unless otherwise stated. 


\section{Background}

For bladder cancer, it is still difficult to predict disease progression and outcome for every individual patient as reliable biomarkers are missing. In the past few years many studies were published, which investigated new potential progression-associated factors [1-5], however prospective validation studies are needed.

For example, aberrantly methylated TBX4 was identified as a novel potential marker for disease progression [1] and Cathepsin E, Maspin, Plk1 and Survivin were proposed as new markers for progression in non-muscle-invasive bladder cancer [2]. Also an involvement of mTOR signalling pathway, as assessed by $\mathrm{S} 6$ protein phosphorylation, seems to be associated with increased disease recurrence, progression and worse disease specific survival [3]. Munksgaard et al. could identify one hitherto unknown gene, ANXA10, which was correlated with shorter progression-free survival when expressed at low levels [4]. Using whole exome next generation sequencing technique, Gui et al. were able to detect for the first time mutations in chromatin remodeling genes, like $U T X$ and $M L L$, which were associated with bladder cancer [5]. Deletions on chromosome 8p are also a hallmark of bladder cancer and seem to be associated with more advanced tumour stage and increased tumour progression [6,7]. We previously found allelic loss on chromosome $8 p$ in $25 \%$ of all investigated bladder cancers, which was significantly correlated with invasive tumour growth and with papillary growth pattern. In this context, the SFRP1 gene was identified as one potential progression marker at $8 \mathrm{p}$ in bladder cancer [8].

The aim of the present study was, to identify new target genes at chromosome 8p, which are affected by chromosomal deletions and which may play a role in general tumour development, progression and outcome of bladder cancer patients.

Therefore, we analysed $9 \mathrm{pTa}$ and $10 \mathrm{pT} 1$ papillary bladder tumours in high-resolution array-based comparative genomic hybridization (aCGH). One promising candidate gene, MTUS1, was selected for further analysis.

\section{Methods}

\section{Patient cohorts and tumour specimen}

For aCGH analysis 9 papillary pTa and 10 papillary pT1 cryo-conserved tumours were randomly chosen from the tissue bank of the Comprehensive Cancer Center ErlangenEMN located at the Institute of Pathology in Erlangen and DNA was isolated as described below. Tissue specimens were investigated by frozen section and all specimens contained at least $80 \%$ tumour cells.

Tissue micro arrays (TMAs) of two different bladder cancer patient cohorts were used for immunohistochemical analysis of MTUS1: group 1 consisted of 85 patients with non-muscle invasive (pTa or pT1) papillary tumours and group 2 of 236 patients with advanced bladder tumours ( $\geq$ pT3 and/or pN1), who all underwent radical cystectomy and received adjuvant chemotherapy. TMAs of the advanced tumour group were available at the Institute of Pathology Erlangen resulting from a previous prospective study [9], originally consisting of 327 patients. Due to tissue availability only a subgroup of 236 patients of the initial cohort was analysed. For this study IRB approval was obtained from the German Association of Urological Oncology (AUO) as well as informed written consent was obtained from all patients of participating local centers and clinics. All relevant patient characteristics and clinico- and histopathological parameters were summarized previously [9].

Papillary bladder tumours were newly assembled for this study from the tumour bank of the Comprehensive Cancer Center Erlangen-EMN located at the Institute of Pathology in Erlangen. Formalin-fixed and paraffin-embedded tumour tissues and corresponding haematoxylin-eosin stained sections were selected, tumour areas were marked and reevaluated according to histopathological stage and grade by two experienced surgical pathologists (AH, JG). Clinical Follow-up data for the papillary tumour group were obtained in collaboration with the Tumorzentrum (TUZ) Erlangen.

Informed written consent was obtained from all patients of the papillary tumour group as well as from aCGH tumour patients, and we obtained approval from the Clinical Ethics Committee of the University Hospital Erlangen for retrospective use of patient material in the context of the Comprehensive Cancer Center-tissue bank.

All relevant patient characteristics, histopathological data and follow-up are shown in Table 1. Additional characteristics of the advanced bladder cancer cohort, used for adjusting to multivariate Cox-regression are shown in Table 2.

\section{Cell lines and transfection}

For functional analysis of MTUS1-expression, the bladder cancer cell lines RT112, RT4, J82 and BFTC905 [10-13] as well as the two presumably normal urothelial cell lines UROtsa and HCV29 were screened using qRT-PCR and Westernblot analysis. UROtsa was isolated from a primary culture of normal human urothelium and immortalized with a construct containing SV40 large T antigen [14]. For HCV29 various characterizations can be found in literature. Riesenberg et al. describes HCV29 as non-malignant cell line of the ureter region [15], whereas other groups designate it as pre-malignant or even malignant cell line [16-18]. Thus, it seems more appropriate to term these apparently normal cell lines UROtsa and HVC29 as immortal urothelial cell lines with no or low malignant potential. Cells were cultured in RPMI medium supplemented with $10 \%$ fetal calf serum (FCS), 1\% sodium-pyruvate and 1\% Lglutamine at $37^{\circ} \mathrm{C}$ and $5 \% \mathrm{CO}_{2}$. The prostate carcinoma 
Table 1 Patient characteristics

\begin{tabular}{|c|c|c|c|}
\hline & aCGH bladder tumour cohort & Papillary bladder tumour cohort & Advanced bladder tumour cohort \\
\hline Patients & $\mathrm{n}=19$ & $\mathrm{n}=85$ & $n=236$ \\
\hline \multirow[t]{5}{*}{ Age } & Mean: 69.3 years & Mean: 70 years & Mean: 63 years \\
\hline & Median: 68 years & Median: 71 years & Median: 63.5 years \\
\hline & ( \pm 9.9 years) & $( \pm 11.6$ years $)$ & ( \pm 8.4 years $)$ \\
\hline & Range: 53 - 95 years & Range: 29-97 years & Range: $38-81$ years \\
\hline & & & n.a. $n=4$ \\
\hline \multirow[t]{3}{*}{ Gender } & Female: $n=5$ & Female: $\mathrm{n}=22$ & Female: $n=56$ \\
\hline & Male: $n=14$ & Male: $n=63$ & Male: $\mathrm{n}=177$ \\
\hline & & & n.a. $n=3$ \\
\hline \multirow[t]{6}{*}{ Stage } & pTa $n=9$ & PUNLMP $n=1$ & pT1 $n=6$ \\
\hline & $\mathrm{p} T 1 \mathrm{n}=10$ & pTa $n=47$ & pT2 n $=29$ \\
\hline & & pT1 $n=31$ & pT3 $n=141$ \\
\hline & & $\mathrm{pT} 2 \mathrm{n}=4$ & pT4 $n=37$ \\
\hline & & pT3 $n=1$ & n.a. $n=23$ \\
\hline & & pT4 $n=1$ & \\
\hline \multirow[t]{3}{*}{ Grade } & $\lg n=6$ & $\lg n=40$ & $\mathrm{G} 2$, hg $\mathrm{n}=28$ \\
\hline & hg $n=13$ & hg $n=42$ & $\mathrm{G} 3, \mathrm{hg} n=203$ \\
\hline & & n.a. $=3$ & n.a. $n=5$ \\
\hline \multirow[t]{3}{*}{ Follow-up OS } & n.a. & Alive $n=65$ & Alive $n=76$ \\
\hline & & Dead $n=15$ & Dead $n=129$ \\
\hline & & n.a. $n=5$ & \\
\hline \multirow[t]{3}{*}{ Follow-up DSS } & n.a. & Alive $n=70$ & Alive $n=63$ \\
\hline & & Dead $n=8$ & Dead $n=142$ \\
\hline & & n.a. $n=7$ & \\
\hline
\end{tabular}

Abbreviations: $a C G H$ array based comparative genomic hybridization, OS overall survival, DSS disease-specific survival.

cell line LNCaP was used as positive control for MTUS1expression [19].

Transfection was carried out in 6-well plates seeding 300000 cells per well. After 48 hours of cell adhesion MTUS1 was transiently overexpressed in RT112 using the MTUS1 human cDNA clone in pCMV6-XL5 vector (Origene Technologies, Rockville/USA, SC300343, transcript variant $1=$ ATIP3) and MegaTran 1.0 transfection reagent (Origene Technologies) with a ratio of 1:3 (DNA:MegaTran) according to manufacturer's instructions.

\section{DNA-, RNA isolation and cDNA synthesis}

To investigate 19 bladder tumours in aCGH analysis, tumour specimens were manually microdissected and DNA was isolated using the QIAamp DNA Mini Kit (Qiagen, Hilden/Germany) according to manufacturer's protocol. To analyse MTUS1 gene expression with qRT-PCR, RNA was isolated using RNeasy ${ }^{\circ}$ Mini Kit (Qiagen) and cDNA was converted using the RevertAid ${ }^{\text {Tw }} H$ Minus First Strand cDNA Synthesis Kit (Fermentas Life Sciences, St. Leon-Rot/Germany) according to manufacturer's instructions. For cDNA-synthesis $1 \mu \mathrm{g}$ total RNA was used.
DNA- and RNA-quality was controlled using the Multiplate Reader Synergy 2 (BioTek, Bad Friedrichshall/ Germany).

\section{aCGH analysis}

DNA of 19 papillary bladder tumours (500 ng each) was investigated for chromosomal alterations and copy number changes with array-based comparative genomic hybridization (aCGH) using Genome-Wide SNP Array 6.0 (Affymetrix, Munich/Germany) according to manufacturer's protocol. Array chips were scanned with GeneChip Scanner 3000 7G. Hybridization was performed at the IZKF Z3 Core Unit Genomics of the Institute of Human Genetics in Erlangen. Data analysis was performed with Genotyping Console (Affymetrix). Tumour DNAs were compared with DNAs from 167 anonymous healthy controls, which were provided by the IZKF Z3 Core Unit Genomics.

\section{qRT-PCR}

To analyse MTUS1 wildtype mRNA expression in cell lines and to control overexpression of MTUS1 in RT112, 
Table 2 Additional characteristics of the advanced bladder cancer cohort, used for adjusting to multivariate Cox-regression

Histological variant (n)

Common urothelial carcinoma
Plasmocytoid urothelial carcinoma
Micropapillary urothelial carcinoma
n.a.
\[ \text { Type of adjuvant chemotherapy (n) } \]
Gemcitabine-cisplatin
Mono gemcitabine
MVEC
Cisplatin-methotrexate
n.a.

Lymph-node invasion (n)

pNO

pN1

$\mathrm{pN} 2$

pN3

n.a.

P53 expression (n)

$<5 \%$

$\geq 5 \%$

n.a.

Abbreviations: n.a. not available, MVEC methotrexate, vinblastine, epirubicine, cisplatin, $n$ number.

SYBR Green-based quantitative real-time PCR (qRTPCR) was performed in 7500 Fast Real-time PCR-system (Applied Biosystems, Darmstadt/Germany) with standard thermal cycling conditions. For qRT-PCR $25 \mathrm{ng}$ cDNA template, $200 \mathrm{nM}$ MTUS1-Primermix (sense: 5'-AGCTTCGGGACACTTACATT-3', antisense: 5'-A TAGGCCTTCTTTAGCAATTC-3'), 250nM GAPDHprimermix (sense: 5'-TGGTCACCAGGGCTGCTT-3', antisense: $5^{\prime}$ - AGCTTCCCGTTCTCAGCC-3') and $6.25 \mu \mathrm{l}$ SYBR Green Mix $(2 \times)$ was used in a total volume of $12.5 \mu \mathrm{l}$. Data analysis was performed with 7500 Software v2.0.5 (Applied Biosystems) and gene-expression ratios were calculated with $\Delta \Delta \mathrm{C}_{\mathrm{T}}$-method [20].

\section{FGFR3 mutation analysis}

FGFR3 mutation analysis was performed as previously described [21-23]. Extended primers were separated by capillary electrophoresis in the Genetic Analyser 3500 Dx (Applied Biosystems), and the presence or absence of a mutation was indicated by the incorporated wildtype or mutant labelled dideoxy nucleotide.

\section{Western blotting}

To analyze MTUS1 protein expression in cell lines, immunoblotting was performed with $30 \mu \mathrm{g}$ total protein of whole cell lysates after SDS-PAGE on 7.5\% PAA-gels on nitrocellulose membrane using wet blotting method with Mini Protean ${ }^{\circ}$ Tetra System (BioRad Laboratories, Munich/ Germany) according to manufacturer's protocol. Membranes were blocked with Immunoblot Blocking Reagent (Millipore, Billerica/USA) and treated with anti-MTUS1 antibody (mouse IgG clone 1C7, Abnova H00057509-M01, 1:130, 1 hour/RT, contains epitopes against ATIP1 (49 kDa), ATIP3 $(140 \mathrm{kDa})$ and ATIP4 $(59 \mathrm{kDa}))$ or $\beta$-AKTIN (mouse, Sigma-Aldrich, Taufkirchen/Germany, A5441, 1:10 000, 1 hour, RT) and HRP-conjugated secondary antibody (goat-anti-mouse, Dianova/Jackson ImmunoResearch Laboratories, Baltimore/USA, $40 \mathrm{~min}, \mathrm{RT}$ ). Luminescence signal detection was performed using Immobilion Western Chemiluminescent HRP Substrate (Millipore) according to manufacturer's instructions with Fusion FX7 (Vilber-Lourmat, Eberhardzell/Germany). Cell lysates of LNCaP were included as positive control.

\section{Immunohistochemistry}

Immunohistochemistry was performed on formalin-fixed, paraffin-embedded (FFPE-) $4 \mu \mathrm{m}$ TMA sections of tumour tissue specimen transferred to glass slides. TMA construction was performed as described previously $[24,25]$. TMAs were stained with monoclonal mouse anti-MTUS1 antibody (Abnova, Heidelberg/Germany, overnight, RT). This was followed by incubation with secondary rabbit antimouse antibody (1:100 diluted in TRIS-buffer, DakoCytomation, Glostrup/Denmark) for $30 \mathrm{~min}$ at room temperature. Then, slides were incubated for $20 \mathrm{~min}$ with ABC-solution (antibody-biotin-complex VECTASTAIN $^{\circ}$ Elite ABC kit, Vector Laboratories, Burlingame/ USA), followed by a $10 \mathrm{~min}$ incubation with TSA-solution (TSA $^{\mathrm{Tm}}$ indirect, Perkin Elmer, Waltham/Massachusetts) and 20 min reincubation with $\mathrm{ABC}$ according to manufacturer's protocols. AEC-solution (AEC Peroxidase Substrate Kit, Vector Laboratories) was added until staining intensity was sufficient (approx. $10 \mathrm{~min}$ ). Slides were counterstained for 2 min with haemalaun (Carl Roth, Karlsruhe/ Germany) and mounted with Aquatex (Merck, Darmstadt/ Germany).

Stainings were examined and evaluated by an experienced uropathologist $(\mathrm{AH})$ and immunoreactivity (IRS = immune reactive score) was scored as follows: Intensity $(0$ = negative, 1 = weak, 2 = moderate, $3=$ strong $)$ and number of tumour cells (in percent) was determined. Number of stained cells was correlated to numbers from 0 to 4 . No staining of cells was evaluated as $0,<10 \%$ as 1 , $10-50 \%$ as $2,51-80 \%$ as 3 and $81-100 \%$ as 4 . Numbers were multiplied with staining intensity and immunoreactive values between 0 and 12 were created. For MTUS1- 
staining two immunoreactive groups were created: group $1=\operatorname{IRS} 0$, group $2=\operatorname{IRS} 1-12$.

\section{Viability and proliferation assay}

To investigate functional consequences of MTUS1 overexpression, effects on viability and proliferation were analysed. Therefore 15000 cells per well were seeded into white (viability) or clear (proliferation) 96-well plates in RPMI medium. Viability and proliferation were measured after 24 hours with CellTiter-Glo Luminescent Cell Viability Assay (Promega, Mannheim/Germany) and with the colorimetric QIA58 BrdU Cell Proliferation Assay (Merck), respectively, according to manufacturer's protocol using the Multiplate Reader Synergy 2 (BioTek).

\section{Wound-healing assay}

To analyse effects on migration, wound-healing assay was performed using Culture-Inserts for Live Cell Analysis (Ibidi, Martinsried/Germany) and photo documentation with Olympus IX81 (Olympus Europe Holding, Hamburg/ Germany). Transfected and control cells were seeded in culture-inserts with a concentration of 500000 cells $/ \mathrm{ml}$ using $70 \mu \mathrm{l}$ of cell suspension per well. After cells have grown to a dense cell layer, inserts were removed and growth pattern was documented photographically within 24 hours. Area of overgrown surface between transfected cells and controls was compared using Axio Vision Rel 4.8.2 Software (Olympus Europe Holding).

\section{Statistical analysis}

For statistical analysis PASW/SPSS 19.0 (IBM, Armonk/ New York State) was used. To determine statistical significance of differences in functional cell culture experiments, non-parametrical Kruskal-Wallis-test (for k-independent random samples, univariate analysis of variance) was used. To determine MTUS1-dependant survival, Kaplan-Meier analysis was performed using Log-Rank test. Survival probability and survival risk was determined with multivariate Cox-Regression analysis (95\% CI). To correlate patient data amongst each other and to detect significant associations, bivariate correlation with Spearman's rhotest and Chi-square-test was performed. P-values $<0.05$ were considered as statistically significant.

\section{Results}

\section{aCGH analysis}

We analysed a cohort of 9 pTa and 10 pT1 papillary bladder tumours for characteristic chromosomal alterations using aCGH.

Figure 1 depicts chromosome 8 alterations in all investigated tumours in horizontal view. In general pTa tumours (1A) had a smaller number of chromosomal alterations, than pT1 tumours (1B). In pT1 tumours there was an increased occurrence of deletions on chromosome $8 \mathrm{p}$ and of amplifications on $8 \mathrm{q}$ compared to pTa tumours. To find deleted target genes that might identify potentially progressing pTa tumours, we analysed all occurring microdeletions in pTa tumours and compared them with pT1 tumours. We found that two non-invasive tumours showed sporadic deletions on 8p. In pT1 tumours, 6/10 tumours showed almost complete loss of whole chromosome arm 8p and 2/10 tumours showed local microdeletions. Only two pT1 tumours had no detectable deletion on $8 \mathrm{p}$. In Figure $1 \mathrm{C}$ and $\mathrm{D}$, one representative microdeletion on chromosome $8 \mathrm{p} 22$ is shown. Only one pTa tumour $(11 \%, 1 \mathrm{C})$, but five pT1 tumours $(50 \%, 1 \mathrm{D})$ were affected by this heterozygous deletion. At this locus the following candidate target genes were identified: SLC7a2 (solute carrier family 7, member 2), PDGFRL (platelet-derived growth factor receptor-like), MTUS1 (microtubule-associated tumour suppressor 1), FGL1 (fibrinogen-like 1) and PCM1 (pericentriolar material 1). Thereof MTUS1 was the most promising gene, as it was previously described to be a tumour suppressor gene in various malignancies, e.g. pancreatic, ovarian, colon and breast carcinomas [26-29].

As there was no known association between MTUS1 and bladder cancer during time of analysis, we selected this gene for further characterization. In the meantime another study group also found an association between MTUS1 expression and bladder cancer [30].

\section{MTUS1 mRNA and protein expression in cell lines}

We screened four bladder cancer cell lines (RT112, RT4, J82 and BFTC905) as well as two presumably normal and immortalized urothelial cell lines, UROtsa and HCV29, for MTUS1 mRNA expression using qRT-PCR. Quantitative RT-PCR analysis revealed positive MTUS1 mRNA expression in all cell lines investigated with HCV29, RT112 and J82 having the lowest levels and UROtsa having the highest level of all bladder cell lines (Figure 2). Expression level of RT112 was defined as $100 \%$.

These results were in line with western blotting results, where MTUS1 bands could be detected in all cell lines analyzed (Figure 2B). However, depending on the cell type, different protein bands could be detected. The Uniprot database lists a total of 7 known protein isoforms for MTUS1 (http://www.uniprot.org/uniprot/Q9ULD2). For RT112, J82, BFTC905, UROtsa and LNCaP (positive control) a band at around $140 \mathrm{kDa}$ was visible. According to the molecular weight, this band can be attributed to MTUS1 isoform 1 (141 $\mathrm{kDa}, \mathrm{ATIP3a})$ or isoform 2 (136 kDa, ATIP3b). A very distinct band could be observed at $\sim 60 \mathrm{kDA}$ mainly in LNCaP, HCV29 and UROtsa cells. According to the molecular weight, this band can be attributed to MTUS1 isoform 6 (59 kDa, ATIP4). Interestingly, one additional band at approximately $80 \mathrm{kDA}$ was detected in all cell lines with the strongest intensity in RT4 and the lowest in UROtsa. The origin of this band remains 


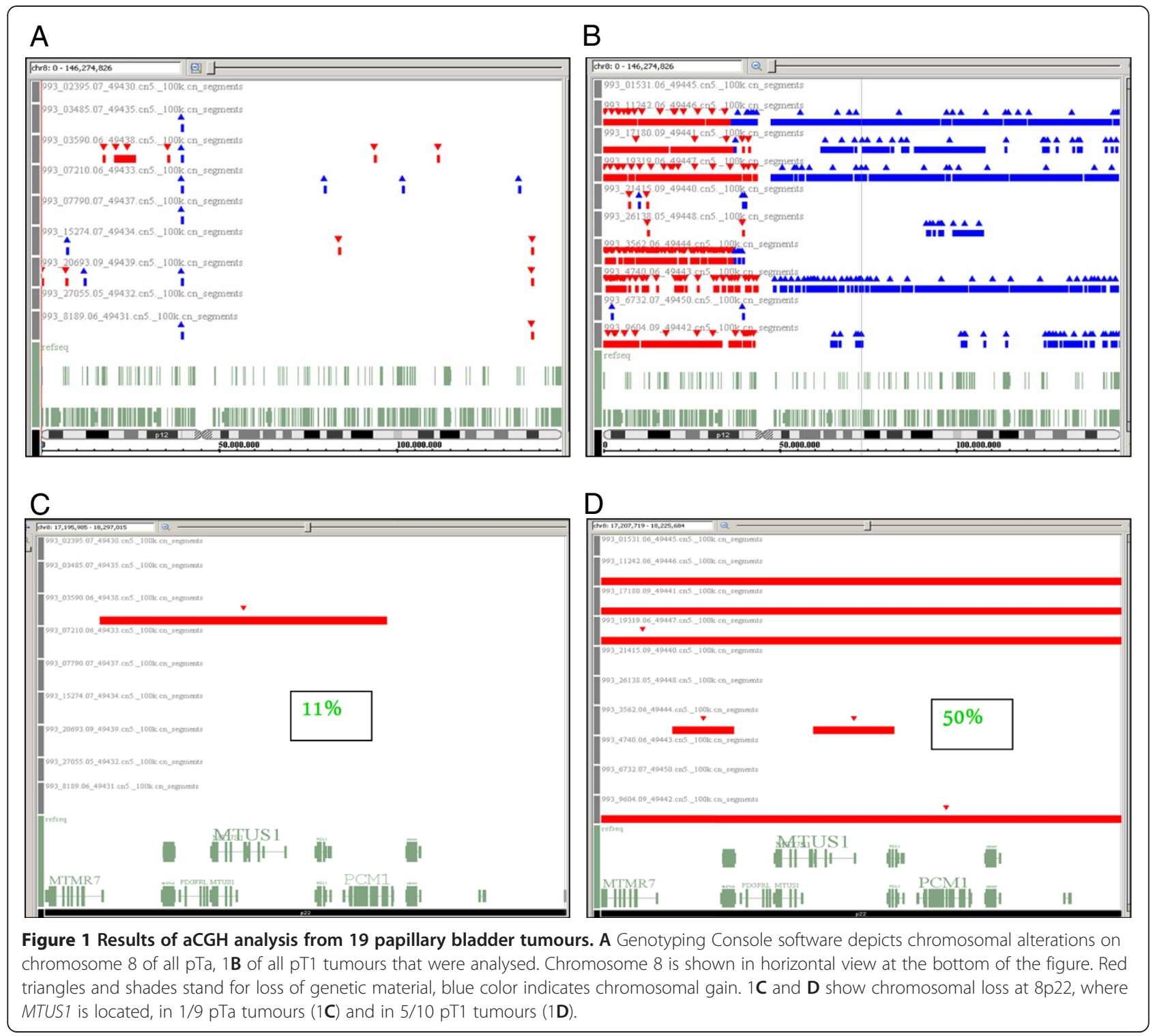

unknown. Although there exists a MTUS1 isoform with a molecular weight of $84 \mathrm{kDa}$ (ATIP2), this known isoform does not contain the protein epitope the antibody was raised against.

\section{Functional analysis after MTUS1 overexpression in RT112} As RT112 had the lowest expression on mRNA level of all investigated bladder cancer cell lines, we selected this cell line for overexpression analysis. Therefore we transiently overexpressed MTUS1 in RT112 and analysed effects on proliferation, viability and wound-healing after 24 hours. For proliferation, we detected an approx. 10\% reduction in MTUS1 overexpressing RT112 cells. This reduction was not statistically significant $(\mathrm{p}=0.6$, data not shown). However, it could be shown that viability was significantly decreased in MTUS1 overexpressing cells compared to control RT112 cells $(p=0.002$, Figure 3A). Regarding wound-healing assay, we found that there was a distinct but not significant difference between MTUS1 overexpressing and wild type RT112 cells ( $\mathrm{p}=0.121)$. In MTUS1-overexpressing cells only $65.9 \%$ of the wound area was overgrown after 24 hours, whereas in wild type cells already $92.4 \%$ of the gap was closed (Figure 3B).

\section{IHC analysis of MTUS1 expression in bladder tumours}

In the papillary bladder cancer group MTUS1 expression was lost in $50.6 \%$ of the tumours (43/85). Immunohistochemical staining showed the following distribution of immunoreactive groups: IRS $0, \mathrm{n}=43$; IRS $2, \mathrm{n}=29$; IRS 4, $\mathrm{n}=8$; IRS 6, $\mathrm{n}=3$; IRS 8, $\mathrm{n}=1$; IRS 9, $\mathrm{n}=1$. MTUS1 was located in the cytoplasm, as expected. Representative examples of negative $(4 \mathrm{~A}, \mathrm{~B})$ and positive $(4 \mathrm{C}, \mathrm{D})$ 


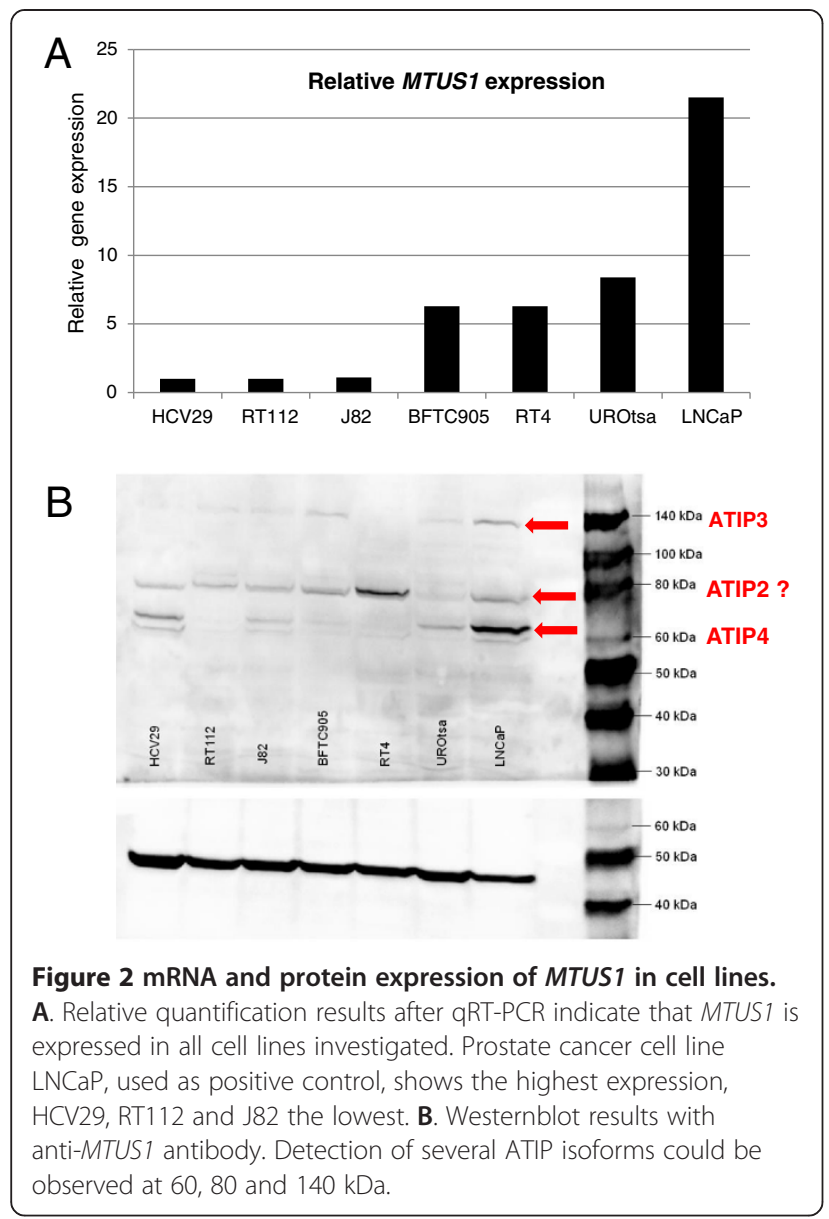

staining in papillary bladder carcinomas are shown in Figure 4. Mean follow-up time was 49.5 months (median 39.1 months). Regarding overall, disease-specific, progression-free, recurrence-free and metastasis-free survival, no significant MTUS1-dependant differences were found.

Interestingly a significant direct correlation between MTUS1-expression and stage, grade, Ki67 and CK20expression was found (Figure 5). MTUS1-expressing tumours showed higher tumour grade $(\mathrm{p}=0.005,5 \mathrm{~A})$ and stage $(\mathrm{p}=0.004,5 \mathrm{~B})$ as well as aberrant expression of differentiation marker CK20 $(\mathrm{p}=0.004,5 \mathrm{C})$ and proliferation marker Ki67 ( $p=0.004,5 \mathrm{D})$. To prove the integrity of our papillary study cohort, we additionally performed FGFR3 mutation analysis (representative examples SNaPshot analysis are shown in Figure 6A and B). It is well-known that FGFR3 mutations occur predominantly in bladder tumours with papillary growth pattern. Those mutations are connected with a lower malignant potential of the bladder tumour as indicated by lower tumour stage and/or grade. Therefore we correlated FGFR3 mutation status with tumour grade. The mutation analysis revealed that the majority of our tumours $(\mathrm{n}=54)$ had at least one mutation, which was

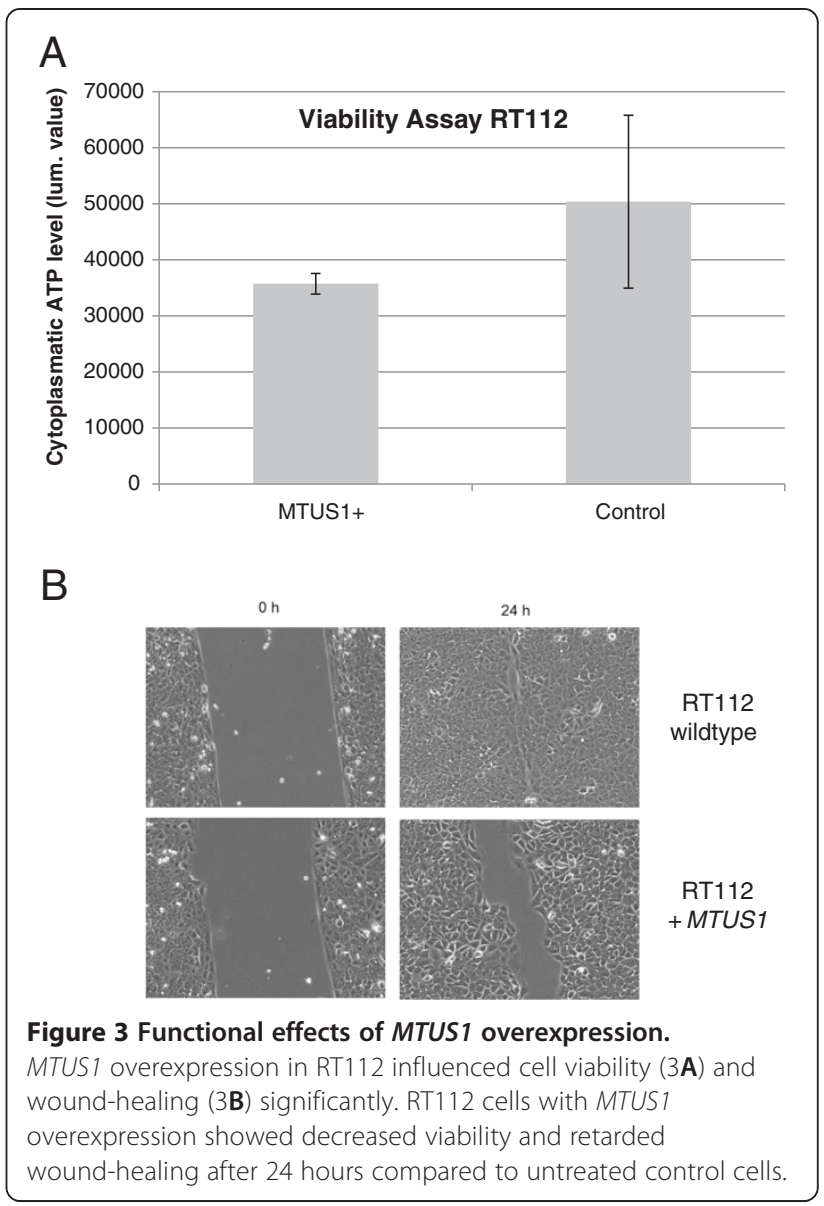

associated with non-invasive growth pattern, whereas only 27/85 tumours had FGFR3 wild type (correlated with more invasive growth, $p=0.059$, Figure $6 \mathrm{C}$ ). Four tumours could not be analysed in FGFR3 mutation analysis. Tumours with FGFR3 mutations showed more MTUS1 expression loss than wild type tumours (Figure 6D). This was in line with the inverse correlations of the other histopathological parameters, as mentioned above.

In the advanced bladder tumour cohort $45.8 \%$ of the tumours (108/236) showed loss of MTUS1 expression and 54\% (128/236) tumours were classified into IRS group 1-12. Immunoreactivity showed the following distribution: IRS $0, \mathrm{n}=108$; IRS $2, \mathrm{n}=52$; IRS $3, \mathrm{n}=2$; IRS 4, $\mathrm{n}=43$; IRS 6, $\mathrm{n}=18$; IRS $8, \mathrm{n}=5$; IRS $9, \mathrm{n}=1$ and IRS $12 \mathrm{n}=7$ ). Representative examples of positive and negative staining of conventional advanced bladder carcinoma are shown in Figure 7A and B. Regarding the distribution of MTUS1 expression within different histopathological subtypes (divided into common urothelial carcinoma (UC), plasmocytoid UC (PUC) and micropapillary UC), a significant expression difference was found $(\mathrm{p}=0.011)$. In all micropapillary tumours $(\mathrm{n}=10)$ strong positive MTUS1-expression was observed in the cytoplasm (Figure 7C). It was also striking that 8/17 PUCs 

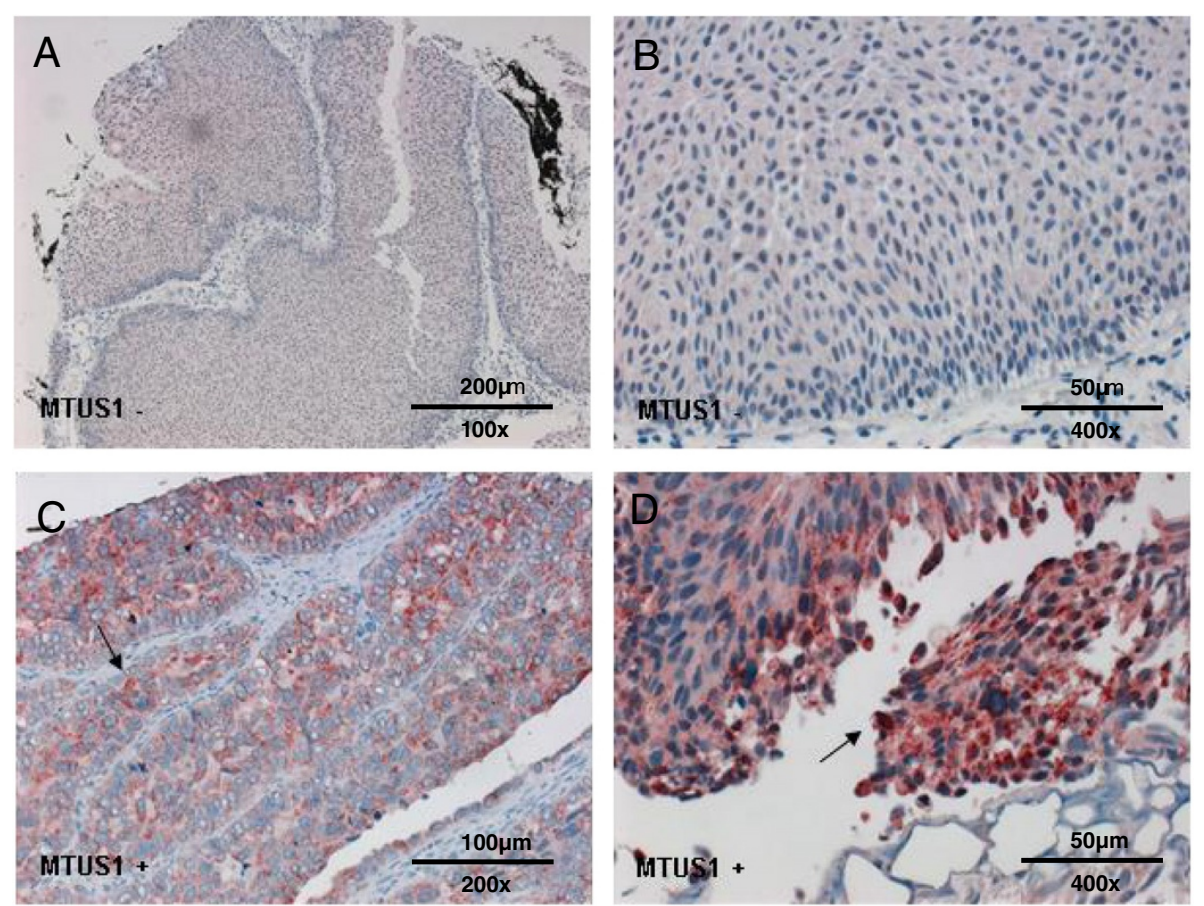

Figure 4 Immunohistochemical expression of MTUS1 in papillary bladder tumours. Representative examples of immunohistochemical stainings of papillary bladder carcinomas with anti-MTUS1 antibody. $\mathbf{A}$ and $\mathbf{B}$ show tumours with negative, $4 \mathbf{C}$ and $\mathbf{D}$ with positive staining. Localization of MTUS1 is in the cytoplasm.
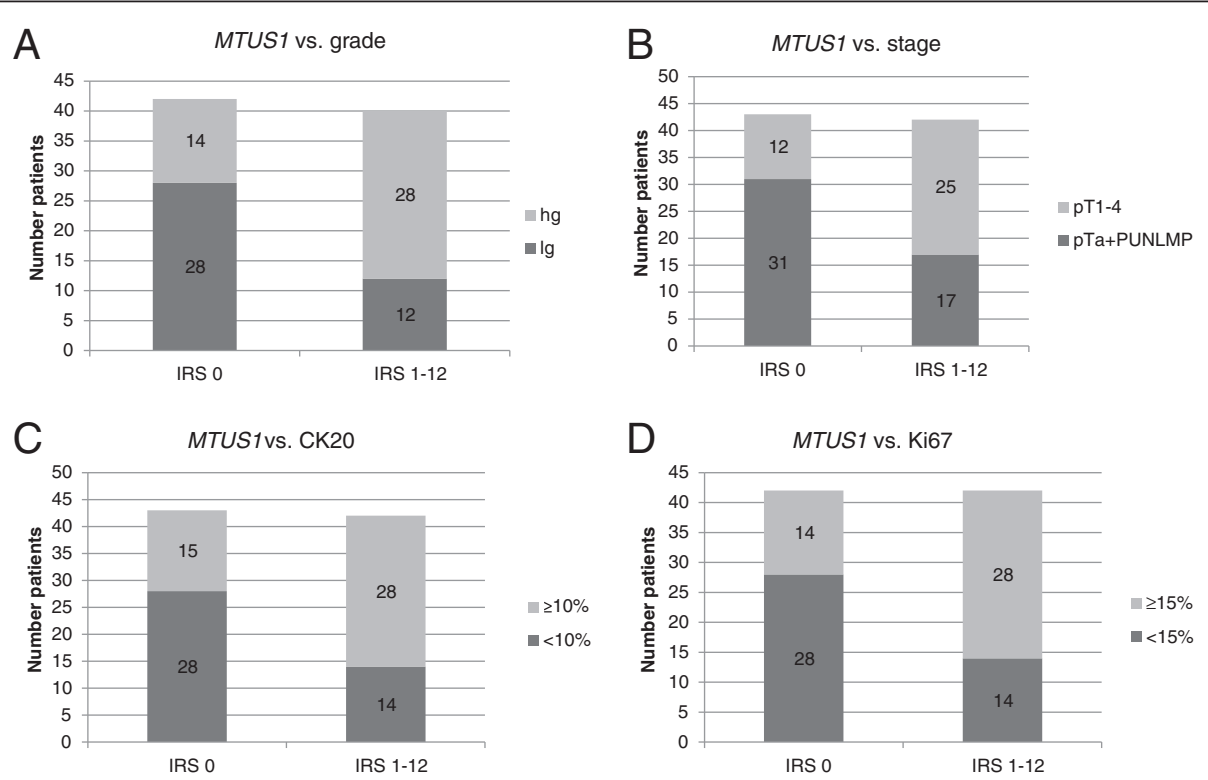

Figure 5 Associations of MTUS1 loss with histopathological parameters in papillary bladder tumours. Significant direct correlation of MTUS1 expression with tumour grade (5A), stage (5B), CK20 (5C) and Ki67 (5D) expression in papillary bladder tumours. MTUS1 loss was associated with decreased malignant potential of the cell as indicated through increased occurrence of low-grade differentiation, non-invasive growth pattern and weak CK20 and Ki67 expression in carcinomas of the IRSO (MTUS1-deficient) group. 

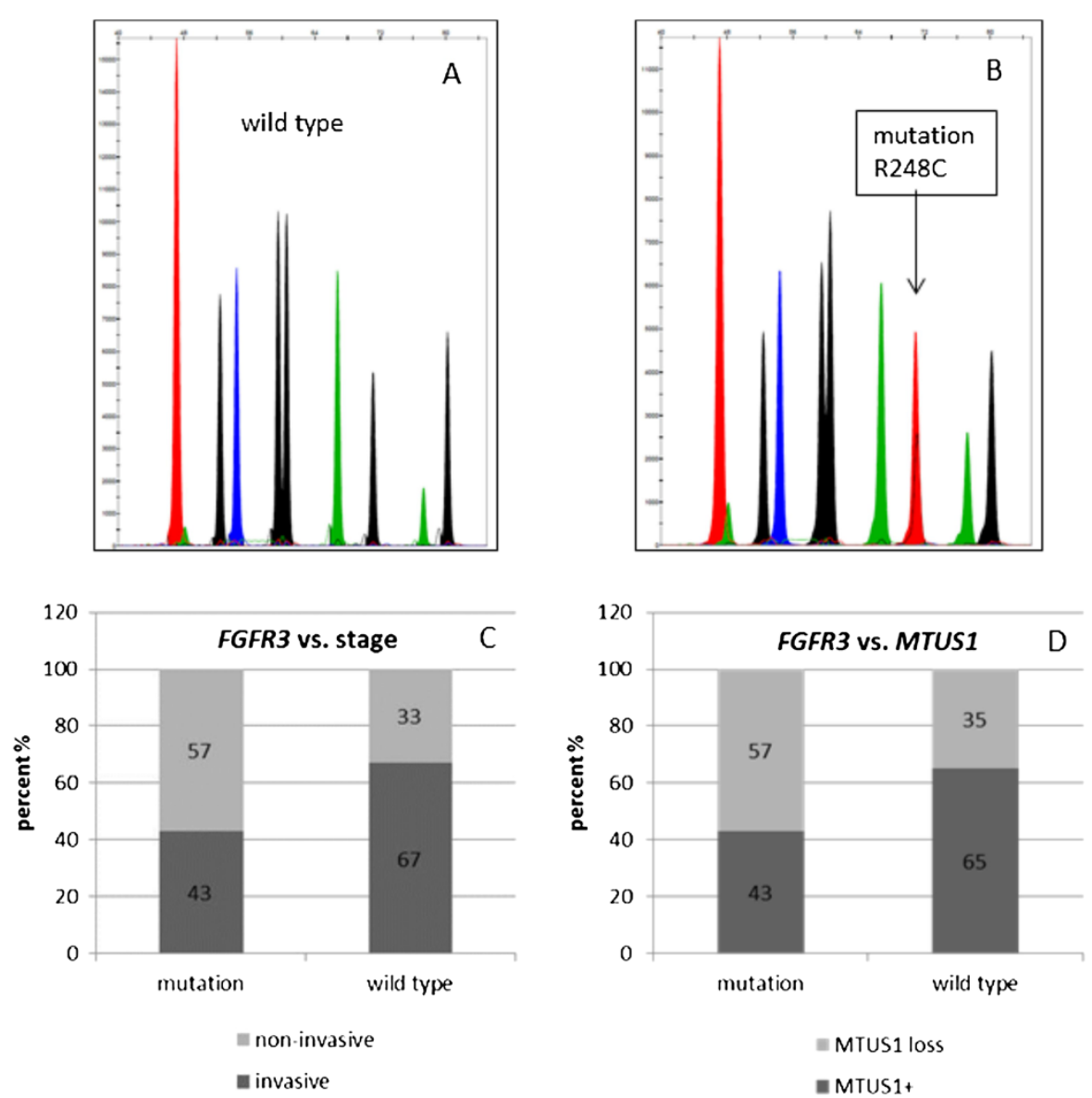

Figure 6 Association of MTUS1 loss with FGFR3 mutations in papillary bladder tumours. FGFR3 mutation analysis in the papillary bladder tumour group. $6 \mathbf{A}$ and $\mathbf{B}$ show representative examples of FGFR3 wildtype (6A) and mutation R248C (6B) sequences. To assess data integrity we correlated FGFR3 status with tumour stage (6C) and then with MTUS1 expression (6D). We showed that the majority of FGFR3 mutation tumours had a predominantly non-invasive growth pattern compared to FGFR3 wildtype tumours, which showed more invasive phenotypes. FGFR3 mutation where, however, correlated with MTUS1 loss.

showed positive MTUS1 expression in the nucleus (Figure 7D), but not in the cytoplasm. The remaining PUCs showed complete loss of expression.

Kaplan-Meier analysis revealed significantly better overall $(\mathrm{p}=0.029)$ and disease-specific $(\mathrm{p}=0.027)$ survival for $\mathrm{pa}-$ tients with MTUS1 expression in the bladder tumour (IRS 1-12). Patients with MTUS1 expression survived for 64 months (OS) and 69 months (DSS), whereas patients without MTUS1 expression showed mean survival of only 46 (OS) and 50 months (DSS), respectively. Also in multivariate Cox-regression analysis with stepwise backward elimination (adjusted to gender, stage, grade, node-invasion, histological subtype, type of chemotherapy and P53 expression), this observation could be confirmed, however not significantly. A hazard ration of 1.507 (95\% CI 0.92-2.46, $\mathrm{p}=0.102)$ and $1.662(95 \% \mathrm{CI} 0.97-2.85, \mathrm{p}=0.066)$ was found for overall and disease-specific survival, respectively. OS and DSS survival curves are shown in Figure 8A to D. Due to availability of survival time and/or status as well as of additional patient characteristics, only 198/236 and 173/236 patients could be analysed in Kaplan-Meier and Coxregression analysis, respectively. Patients with MTUS1 expressing tumours also had better progression-free survival (PFS, mean survival time: 60.5 months, $\mathrm{n}=111$ ) compared to patients with MTUS1 expression loss (46.8 months, $\mathrm{n}=86, \mathrm{p}=0.179$, PFS graphs not shown).

\section{Discussion}

In aCGH we found that pT1 tumours had more genomic aberrations than pTa tumours, which strengthens the hypothesis that bladder tumours accumulate genetic alterations with progression of disease. Regarding chromosome $8 \mathrm{p}$, our results were in line with previous studies, which reported loss of chromosome $8 \mathrm{p}$ as a common event in urothelial carcinomas [31-33]. Our most promising candidate gene identified in aCGH at $8 \mathrm{p} 22$, MTUS1, is known to be downregulated in other cancer entities, such as pancreatic, ovarian, colon, breast and prostate cancer 

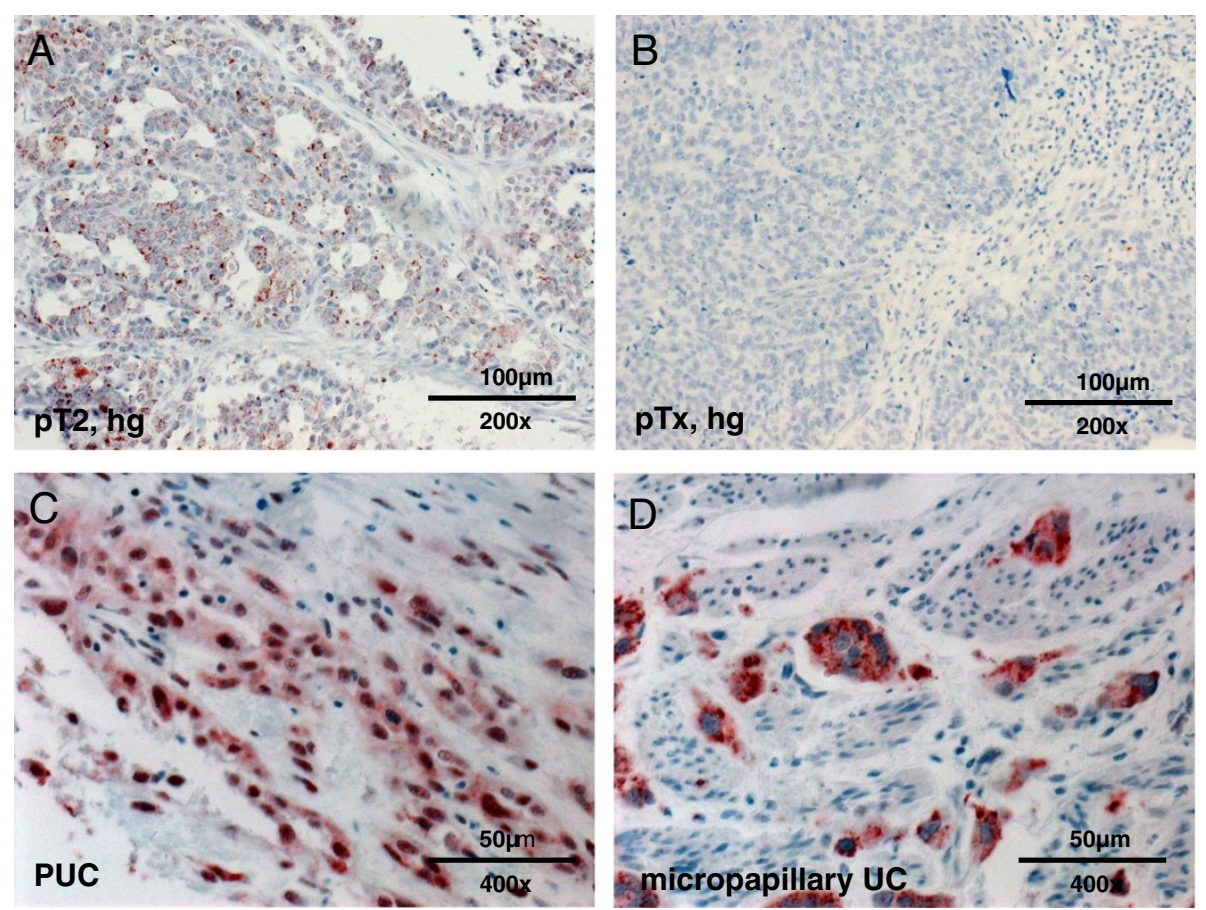

Figure 7 Immunohistochemical expression of MTUS1 in advanced bladder tumours. Representative examples of immunohistochemical stainings in advanced bladder tumours. 7A shows positive, 7B negative staining in common urothelial carcinoma. In 7C positive nuclear staining in plasmocytoid carcinoma of the bladder is shown. In all micropapillary urothelial carcinomas positive cytoplasmatic staining could be observed (7D).
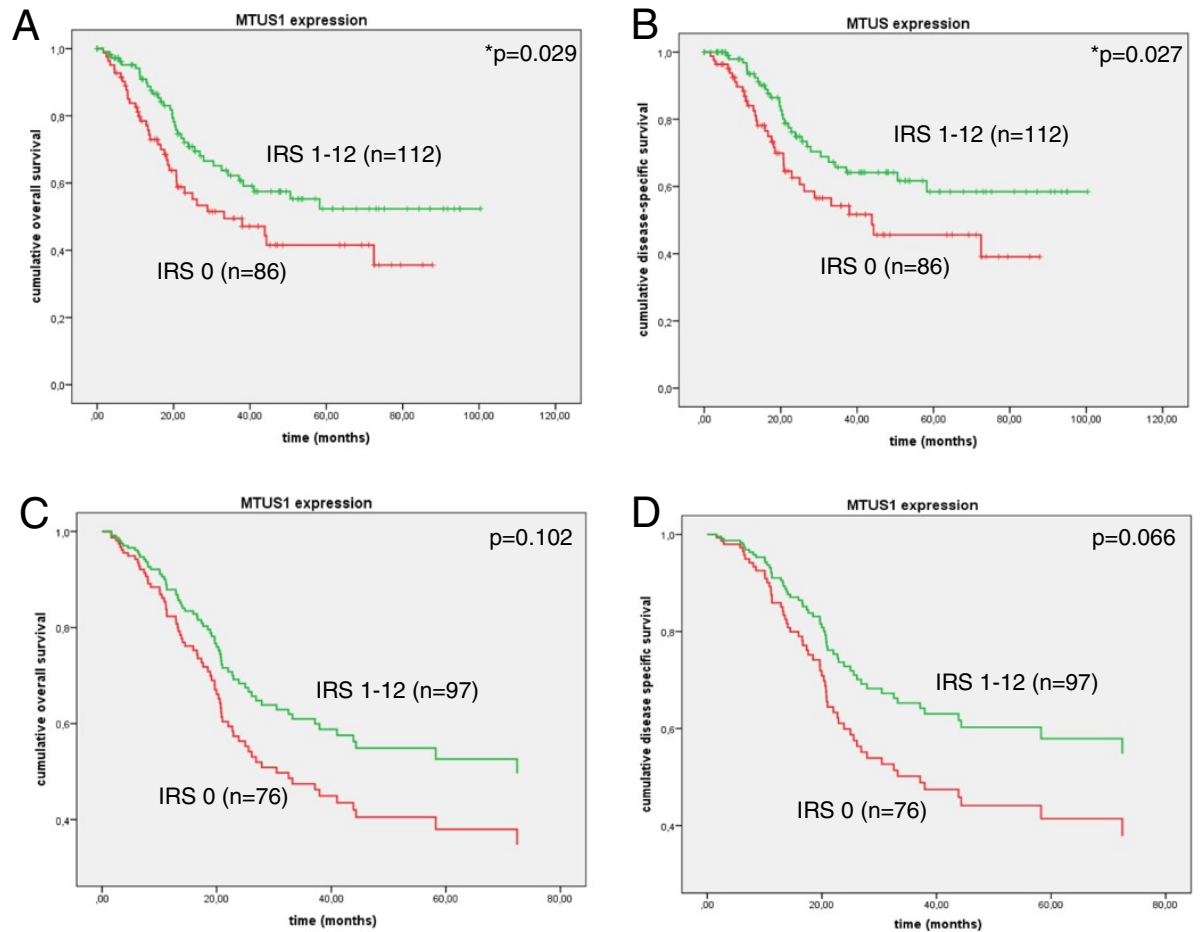

Figure 8 Survival curve analysis in the advanced tumour cohort. $8 \mathbf{A}$ and $\mathbf{B}$ show Kaplan-Meier curves for overall (8A) and disease specific (8B) survival. Patients with positive MTUS1 expression in the tumour (green) have better overall- and disease specific survival, than tumours with MTUS1 expression loss (red). Multivariate Cox-regression analysis (stepwise backward exclusion) for overall (8C) and disease-specific survival (8D) confirmed Kaplan-Meier findings. 
Table 3 Summary of ATIP isoforms and their associated transcripts and proteins (Uniprot, Q9ULD2)

\begin{tabular}{lllll}
\hline MTUS1-Isoforms & Protein-variant & mRNA & Protein & Molecular weight \\
\hline 1 & ATIP3a & $6435 \mathrm{bp}$ & $1270 \mathrm{aa}$ & $141 \mathrm{kDa}$ \\
2 & ATIP3b & $6273 \mathrm{bp}$ & $1216 \mathrm{aa}$ & $136 \mathrm{kDa}$ \\
3 & ATIP1 & $3819 \mathrm{bp}$ & $436 \mathrm{aa}$ & $51 \mathrm{kDa}$ \\
4 & $?$ & $3160 \mathrm{bp}$ & $342 \mathrm{aa}$ & $38 \mathrm{kDa}$ \\
5 & ATIP2 & $2787 \mathrm{bp}$ & $770 \mathrm{aa}$ & $84 \mathrm{kDa}$ \\
6 & ATIP4 & $4022 \mathrm{bp}$ & 517 aa & $59 \mathrm{kDa}$ \\
7 & $?$ & $2667 \mathrm{bp}$ & $415 \mathrm{aa}$ & $48 \mathrm{kDa}$ \\
\hline
\end{tabular}

Abbreviations: ATIP Angiotensin II AT2 receptor-interacting protein, $b p$ base pairs, $a a$ amino acids, $k D a$ kilo Dalton.

[19,26-29]. To clarify its role in bladder cancer, we further analysed MTUS1 in cell culture and immunohistochemical experiments.

MTUS1 (mitochondrial or microtubulus-associated tumour suppressor 1) is located at chromosome 8p21.3-22 (17.501.304-17.658.426, NCBI Genbank ID 57509) and spans $157 \mathrm{kbp}$ (including UTRs) and $110 \mathrm{kbp}$ (coding region, UCSC Genome browser, uc003wxv.3) including 17 exons. Use of alternative exons leads to transcription of 30 different mRNAs and Uniprot describes seven functional MTUS1 protein isoforms which are summarized in Table 3. The gene products are designated as ATIPs (angiotensin II AT2 receptor-interacting proteins) or as ATBPs (AT2-receptor binding-protein) and the name is derived from their function as interaction-partners of AT2-receptors of the renin-angiotensin-aldosterone system. Here ATIP mediates AT2-receptor activation and inhibition of AT1 receptor activity. As antagonist of the AT1 receptor, the AT2 receptor, enhanced through binding of ATIP, induces antiproliferative and anti-apoptotic effects [34]. All ATIPs share one large C-terminal coiled-coil domain, which enables homo- and hetero-dimerization as well as their interaction with the AT2 receptor. The ATIP-proteins interact with the $\mathrm{C}$-terminus of the receptor and further support its capability to inhibit ERK2-activity of the classical MAP-kinasesignalling pathway as well as inhibition of growth factorinduced autophosphorylation of receptor tyrosine kinases [35]. Additionally, it could be demonstrated that ATIP3 is located at the centrosome of the cell and plays an important role in microtubulus-dynamics and mitosis. Overexpression of ATIP3 led to extension of metaphase through modulation of the spindle-checkpoint signalling pathway and is considered as one potential therapeutic effector in metastatic breast cancer [36]. This biological function of MTUS1/ATIP might be also one explanation for the decreased viability in RT112 bladder cancer cells after overexpression of MTUS1. The distinct but not significant reduction of wound-healing behavior might be a consequence of reduced viability.

MTUS1 was first described as a tumour suppressor gene in a study from Seibold et al. [26] where its function was investigated in pancreatic carcinoma cell lines as well as in several normal tissues. It could be shown that MTUS1 was expressed in all investigated normal tissues, such as heart muscle, brain or kidney.

MTUS1 isoforms can be classified into five groups of ATIPs: ATIP1 (436aa, $51 \mathrm{kDa})$, ATIP2 (770aa, $84 \mathrm{kDa}$ ), ATIP $3 a$ and $b$ (1270aa, $141 \mathrm{kDa}$ and 1216aa, $136 \mathrm{kDa}$ ) and ATIP4 (517aa, $59 \mathrm{kDa}$ ). Those transcripts show an unequal distribution in human tissue. ATIP $3 a$ and $b$ seem to be the most common variants and they can be found in almost all human tissues. ATIP3 is also designated as canonical MTUS1 protein variant and is the predominant form reported to be expressed in the bladder [37]. Therefore, ATIP3 was used for overexpression in RT112. ATIP1 and 4 are the predominant forms in the brain. About the distribution of ATIP2 in human tissue not much information is available to date [37]. According to our western blot results it seems likely that, depending on the cell line, the ATIP variants $3(\sim 140 \mathrm{kDa})$ and $4(\sim 59 \mathrm{kDa})$ are expressed in bladder cancer cell lines in different concentrations. ATIP1 (49 kDa), however, seems not to be expressed in bladder cancer cell lines at all. The western blot also shows one distinct band at $\sim 80 \mathrm{kDa}$. According to Uniprot the MTUS1 isoform ATIP2 has a molecular weight of approximately $80 \mathrm{kDa}$. However the antibody contains no epitope for this isoform: the origin of the $80 \mathrm{kDa}$ band still remains unclear. In future experiments it would be important to distinguish the expression levels of each ATIP protein separately, e.g. by usage of ATIP isoform-specific antibodies.

In immunohistochemical analysis we found that MTUS1 expression was lost in $50.6 \%$ of all papillary and in $45.8 \%$ of all advanced bladder tumours. This loss might be the result of chromosomal deletions at $8 \mathrm{p} 22$, as shown in aCGH. Also epigenetic changes, like binding of microRNAs or promoter hypermethylation might inhibit gene transcription and thus protein expression. In papillary bladder cancers, survival was not influenced, however a direct correlation with stage, grade, Ki67 and CK20 expression was found. This indicates that papillary tumours with retained MTUS1 expression have higher malignant potential than MTUS1-deficient tumours and that MTUS1 should be considered more as an oncogene rather than a 
tumour suppressor gene. However, MTUS1 expression did not influence survival and thus does not seem to be important for prognosis or disease progression in the papillary pathway of bladder cancer development. Our findings regarding papillary tumours make it very likely that MTUS1 does not act as a classical tumour suppressor and make a role as new potential progression marker in papillary bladder cancer very unlikely.

Although we could find complete loss of MTUS1 protein expression in almost $50 \%$ of the cases in both bladder tumour cohorts, survival was only influenced in the advanced bladder cancer group. Here expression loss was associated with worse OS and DSS, indicating that MTUS1 acts as a classical tumour suppressor gene and that it might be a new target gene at chromosome $8 \mathrm{p}$ as well as an independent prognostic factor in advanced bladder cancer. These data argue that MTUS1 loss could be important in the development of non-papillary bladder cancer from CIS, which should be investigated in further experiments. It might also be likely that MTUS1 acts as a chemotherapy-response-predictor, as all investigated patients underwent chemotherapy. Additionally, MTUS1 appears to play a major role in two variants of rare advanced and very aggressive bladder tumours. In plasmocytoid urothelial carcinomas MTUS1 was either found in the nucleus or no expression was detected. In micropapillary tumours only positive MTUS1 expression was found, which, in this entity, cannot be responsible for decreased malignancy, as this variant is one of the most aggressive tumour types found in the bladder. It would be interesting to clarify the biological function of MTUS1 especially in PUCs and in micropapillary carcinomas, particularly in regard to the occurrence of mutations. One study identified five major nucleotide substitutions in ATIP3 exons in hepatocellular carcinoma [38]. For bladder cancer, however, no mutation analysis data for MTUS1 is available yet.

In addition to our findings, one recently released study found a correlation of reduced MTUS1 mRNA expression with poor prognosis in bladder cancer patients [30]. The patient cohort, however, was more heterogeneous than ours and comprised all kinds of transitional cell carcinomas of the bladder, ranging from pTa to pT4 and including also CIS. This study revealed equally, that MTUS1 is an independent prognostic factor for DSS in bladder cancer.

\section{Conclusions}

In summary, MTUS1/ATIP was identified as a tumor suppressor gene in cultured bladder cancer cells and in patients with advanced bladder cancers. Although MTUS1/ ATIP loss was detected in approximately $50 \%$ of all investigated bladder cancers, there was only a significant association with worse OS and DSS in advanced bladder carcinomas, but not in papillary bladder carcinomas. This might be due to two different molecular pathways that lead to the development of either frequently recurring papillary or highly malignant solid bladder cancers. In future experiments we want to determine the expression level of potential MTUS1-binding microRNAs and analyse promoter methylation and mutation status of MTUS1 in bladder tumour specimen. We further want to reveal the reason for the frequent loss of MTUS1/ ATIP in bladder cancer and the differences between papillary, micropapillary and other advanced bladder cancers.

\section{Abbreviations}

ATIP: Angiotensin II AT2 receptor interacting protein; MTUS1: Microtubulusassociated tumour suppressor 1; OS: Overall survival; DSS: Disease specific survival; aCGH: Array comparative genomic hybridisation; aa: Amino acid(s); bp: Basepair(s); Da: Dalton; $\mu$ : Micro; n: Nano; s: Second(s); min: Minute(s); h: Hour(s); ${ }^{\circ} \mathrm{C}$ : Degree(s) celsius.

\section{Competing interests}

The author's declare that they have no conflict of interest.

\section{Authors' contributions}

AR coordinated development of papillary bladder tumour tissue micro array, performed DNA- and RNA-isolation, cell culture experiments, GRT-PCR, statistical analysis, data interpretation and aCGH data analysis and participated in immunohistochemical staining, study conception and drafted the manuscript. SH performed immunohistochemical staining and analysis and participated in cell culture experiments, qRT-PCR, statistical analysis, data interpretation and aCGH data analysis. JG participated in histological evaluation of papillary bladder tumours. AE carried out aCGH analysis within the IZKF core unit Z3 Affymetrix-Chip-Analysen. SW participated in survival curve generation and analysis and provided LNCaP positiv control cell line and critically revised the manuscript. HT participated in Kaplan-Meier and statistical analysis and critically revised the manuscript. PG participated in study design, helped to acquire patient data. BW participated in study design, helped to acquire patient data. MS was the principle investigator of the AUO trial and provided paraffine blocks for the advanced bladder cancers (advanced TMA cohort). JL was conducting patient data requisition of the AUO trial (advanced TMA cohort). SP helped to acquire patient data for the papillary TMA cohort. AH helped to draft the manuscript, participated in study design and histological evaluation and supervised the study. RS conceived of, coordinated and supervised the study, participated in TMA development and helped to draft the manuscript. All authors read and approved the final manuscript.

\section{Acknowledgements}

This study was supported by a grant of the Interdisziplinäres Zentrum für Klinische Forschung of the University Hospital Erlangen to PJG, BW, AH and RS and by a grant to AR of the Bavarian Equal Opportunities Sponsorship Förderung von Frauen in Forschung und Lehre (FFL) - Promoting Equal Opportunities for Women in Research and Teaching.

We are grateful to Verena Popp, Yvonne Sauermann, Birgit Meyer, Rudolf Jung and Petra Rothe for their excellent technical assistance. Further the authors thank Stefan Schick from the Tumor Zentrum Erlangen for his help with patient follow-up data.

\section{Author details}

${ }^{1}$ Institute of Pathology, University Hospital Erlangen, Krankenhausstr. 8-10, 91054 Erlangen, Germany. ${ }^{2}$ Institute of Human Genetics, Friedrich-Alexander Universität Erlangen-Nürnberg, Schwabachanlage 10, 91054 Erlangen, Germany. ${ }^{3}$ Department of Urology, University Hospital Erlangen, Krankenhausstr. 12, 91054 Erlangen, Germany. ${ }^{4}$ Clinic for Urology and Children's Urology, University Hospital Saarland, Kirrberger Strasse, 66421 Homburg/Saar, Germany. ${ }^{5}$ Urology Practice Prüner Gang, Prüner Gang 15, 24105 Kiel, Germany. ${ }^{6}$ Tumour Zentrum, Friedrich-Alexander Universität Erlangen-Nürnberg, Carl-Thiersch-Str. 7, 91052 Erlangen, Germany. 
Received: 9 October 2013 Accepted: 12 March 2014

Published: 20 March 2014

\section{References}

1. Reinert T, Modin C, Castano FM, Lamy P, Wojdacz TK, Hansen LL, Wiuf C, Borre M, Dyrskjot L, Orntoft TF: Comprehensive genome methylation analysis in bladder cancer: identification and validation of novel methylated genes and application of these as urinary tumor markers. Clin Cancer Res 2011, 17:5582-5592.

2. Fristrup N, Ulhoi BP, Birkenkamp-Demtroder K, Mansilla F, Sanchez-Carbayo M, Segersten U, Malmstrom PU, Hartmann A, Palou J, Alvarez-Mugica M, Zieger K Borre M, Ornthoft TF, Dyrskjot L: Cathepsin E, maspin, Plk1, and survivin are promising prognostic protein markers for progression in non-muscle invasive bladder cancer. Am J Pathol 2012, 180:1824-1834.

3. Park SJ, Lee TJ, Chang IH: Role of the mTOR pathway in the progression and recurrence of bladder cancer: an immunohistochemical tissue microarray study. Korean J Urol 2011, 52:466-473.

4. Munksgaard PP, Mansilla F, Brems Eskildsen AS, Fristrup N, Birkenkamp-Demtroder K, Ulhoi BP, Borre M, Agerbaek M, Hermann GG, Orntoft TF, Dyrskjot L: Low ANXA10 expression is associated with disease aggressiveness in bladder cancer. Br J Cancer 2011, 105:1379-1387.

5. Gui Y, Guo G, Huang Y, Hu X, Tang A, Gao S, Wu R, Chen C, Li X, Zhou L, He M, Li Z, Sun X, Jia W, Chen J, Yang S, Zhou F, Zhao X, Wan S, Ye R, Liang C, Liu Z, Huang P, Liu C, Jiang H, Wang Y, Zheng H, Sun L, Liu X, Jiang Z, et al: Frequent mutations of chromatin remodeling genes in transitional cell carcinoma of the bladder. Nat Genet 2011, 43:875-878.

6. Wolff EM, Liang G, Jones PA: Mechanisms of disease: genetic and epigenetic alterations that drive bladder cancer. Nat Clin Pract Urol 2005, 2:502-510

7. Williams SV, Platt FM, Hurst CD, Aveyard JS, Taylor CF, Pole JC, Garcia MJ, Knowles MA: High-resolution analysis of genomic alteration on chromosome arm 8p in urothelial carcinoma. Genes Chromosomes Cancer 2010, 49:642-659.

8. Stoehr R, Wissmann C, Suzuki H, Knuechel R, Krieg RC, Klopocki E, Dahl E, Wild P, Blaszyk H, Sauter G, Simon R, Schmitt R, Zaak D, Hofstaedter F, Rosenthal A, Baylin SB, Pilarsky C, Hartmann A: Deletions of chromosome $8 p$ and loss of sFRP1 expression are progression markers of papillary bladder cancer. Lab Invest 2004, 84:465-478.

9. Lehmann J, Retz M, Wiemers C, Beck J, Thuroff J, Weining C, Albers P, Frohneberg D, Becker T, Funke PJ, Walz P, Langbein S, Reiher F, Schiller M, Miller K, Roth S, Kälble T, Sternberg D, Wellek S, Stöckle M: Adjuvant cisplatin plus methotrexate versus methotrexate, vinblastine, epirubicin, and cisplatin in locally advanced bladder cancer: results of a randomized, multicenter, phase III trial (AUO-AB 05/95). J Clin Oncol 2005, 23:4963-4974.

10. Hatina J, Huckenbeck W, Rieder H, Seifert HH, Schulz WA: Bladder carcinoma cell lines as models of the pathobiology of bladder cancer. Review of the literature and establishment of a new progression series. Urologe A 2008, 47:724-734.

11. Masters JR, Hepburn PJ, Walker L, Highman WJ, Trejdosiewicz LK, Povey S, Parkar M, Hill BT, Riddle PR, Franks LM: Tissue culture model of transitional cell carcinoma: characterization of twenty-two human urothelial cell lines. Cancer Res 1986, 46:3630-3636.

12. Rieger KM, Little AF, Swart JM, Kastrinakis WV, Fitzgerald JM, Hess DT, Libertino JA, Summerhayes IC: Human bladder carcinoma cell lines as indicators of oncogenic change relevant to urothelial neoplastic progression. Br J Cancer 1995, 72:683-690.

13. Tzeng CC, Liu HS, Li C, Jin YT, Chen RM, Yang WH, Lin JS: Characterization of two urothelium cancer cell lines derived from a blackfoot disease endemic area in Taiwan. Anticancer Res 1996, 16:1797-1804.

14. Rossi MR, Masters JR, Park S, Todd JH, Garrett SH, Sens MA, Somji S, Nath J, Sens DA: The immortalized UROtsa cell line as a potential cell culture model of human urothelium. Environ Health Perspect 2001, 109:801-808.

15. Riesenberg R, Fuchs C, Kriegmair M: Photodynamic effects of 5aminolevulinic acid-induced porphyrin on human bladder carcinoma cells in vitro. Eur J Cancer 1996, 32A:328-334.

16. Ottesen SS, Ahrenkiel V, Kieler J: Recombinant human interferon gamma exerts an anti-proliferative effect and modulates the expression of human leukocyte antigens $A, B, C$ and $D R$ in human urothelial cell lines. Cancer Immunol Immunother 1990, 31:93-98.

17. Pape GR, Troye M, Perlmann P: Heterogeneity and mechanism of action of human natural killer lymphocytes: differential distribution of receptors for Helix pomatia haemagglutinin (HP receptors). Scand J Immunol 1979, 10:109-118.

18. Larsen JK, Christensen IJ, Kieler J: Cell cycle perturbation by sodium butyrate in tumorigenic and non-tumorigenic human urothelial cell lines assessed by flow cytometric bromodeoxyuridine/DNA analysis. Cell Prolif 1995, 28:359-371.

19. Louis SN, Chow L, Rezmann L, Krezel MA, Catt KJ, Tikellis C, Frauman AG, Louis WJ: Expression and function of ATIP/MTUS1 in human prostate cancer cell lines. Prostate 2010, 70:1563-1574.

20. Schmittgen TD, Livak KJ: Analyzing real-time PCR data by the comparative C(T) method. Nat Protoc 2008, 3:1101-1108.

21. Koufou S, Lunz JC, Borchardt A, Keck B, Kneitz B, Gaisa NT, Hafner C, Giedl C, Rau TT, Rogler A, Wieland WF, Hartmann A, Stoehr R: Mutational activation of FGFR3 is not involved in the development of prostate cancer. Pathobiology 2010, 77:249-252.

22. Van Oers JM, Lurkin I, Van Exsel AJ, Nijsen Y, Van Rhijn BW, van der Aa MN, Zwarthoff EC: A simple and fast method for the simultaneous detection of nine fibroblast growth factor receptor 3 mutations in bladder cancer and voided urine. Clin Cancer Res 2005, 11:7743-7748.

23. Hafner C, Van Oers JM, Vogt T, Landthaler M, Stoehr R, Blaszyk H, Hofstaedter F, Zwarthoff EC, Hartmann A: Mosaicism of activating FGFR3 mutations in human skin causes epidermal nevi. J Clin Invest 2006, 116:2201-2207.

24. Bubendorf L, Nocito A, Moch H, Sauter G: Tissue microarray (TMA) technology: miniaturized pathology archives for high-throughput in situ studies. J Pathol 2001, 195:72-79.

25. Klopocki E, Kristiansen G, Wild PJ, Klaman I, Castanos-Velez E, Singer G, Stohr R, Simon R, Sauter G, Leibiger H, Essers L, Weber B, Hermann K, Rosenthal A, Hartmann A, Dahl E: Loss of SFRP1 is associated with breast cancer progression and poor prognosis in early stage tumors. Int J Oncol 2004, 25:641-649.

26. Seibold S, Rudroff C, Weber M, Galle J, Wanner C, Marx M: Identification of a new tumor suppressor gene located at chromosome 8p21.3-22. FASEB J 2003, 17:1180-1182.

27. Pils D, Horak P, Gleiss A, Sax C, Fabjani G, Moebus VJ, Zielinski C, Reinthaller A, Zeillinger R, Krainer M: Five genes from chromosomal band 8p22 are significantly down-regulated in ovarian carcinoma: N33 and EFA6R have a potential impact on overall survival. Cancer 2005, 104:2417-2429.

28. Zuern C, Heimrich J, Kaufmann R, Richter KK, Settmacher U, Wanner C, Galle J, Seibold S: Down-regulation of MTUS1 in human colon tumors. Oncol Rep 2010, 23:183-189.

29. Rodrigues-Ferreira S, Di Tommaso A, Dimitrov A, Cazaubon S, Gruel N, Colasson H, Nicolas A, Chaverot N, Molinie V, Reyal F, Sigal-Zafrani B, Terris B, Delattre O, Radnanyi F, Perez F, Vincent-Salomon A, Nahmias C: $8 p 22$ MTUS1 gene product ATIP3 is a novel anti-mitotic protein underexpressed in invasive breast carcinoma of poor prognosis. PLOS One 2009, 4:e7239.

30. Xiao J, Chen JX, Zhu YP, Zhou LY, Shu QA, Chen LW: Reduced expression of MTUS1 mRNA is correlated with poor prognosis in bladder cancer. Oncol Lett 2012, 4:113-118.

31. Knowles MA, Shaw ME, Proctor AJ: Deletion mapping of chromosome 8 in cancers of the urinary bladder using restriction fragment length polymorphisms and microsatellite polymorphisms. Oncogene 1993, 8:1357-1364.

32. Takle LA, Knowles MA: Deletion mapping implicates two tumor suppressor genes on chromosome $8 p$ in the development of bladder cancer. Oncogene 1996, 12:1083-1087.

33. Choi C, Kim MH, Juhng SW, Oh BR: Loss of heterozygosity at chromosome segments $8 p 22$ and $8 p 11.2-21.1$ in transitional-cell carcinoma of the urinary bladder. Int I Cancer 2000, 86:501-505

34. Rodrigues-Ferreira S, Nahmias C: An ATIPical family of angiotensin II AT2 receptor-interacting proteins. Trends Endocrinol Metab 2010, 21:684-690.

35. Nouet S, Amzallag N, Li JM, Louis S, Seitz I, Cui TX, Alleaume AM, Di Benedetto M, Boden C, Masson M, Strosberg AD, Horiuchi M, Couraud PO, Nahmias C: Transinactivation of receptor tyrosine kinases by novel angiotensin II AT2 receptorinteracting protein, ATIP. J Biol Chem 2004, 279:28989-28997.

36. Molina A, Velot L, Ghouinem L, Abdelkarim M, Bouchet BP, Luissint AC, Bouhlel I, Morel M, Sapharikas E, Di Tommaso A, Honore S, Braquer D, Gruel N, Vincent-Salomon A, Delattre O, Sigal-Zafrani B, Andre F, Terris B, Akhmanova A, Di Benedetto M, Nahmias C, Rodriques-Ferreira S: ATIP3, a novel prognostic marker of breast cancer patient survival, limits cancer cell 
migration and slows metastatic progression by regulating microtubule dynamics. Cancer Res 2013, 73:2905-2915.

37. Di Benedetto M, Bieche I, Deshayes F, Vacher S, Nouet S, Collura V, Seitz I, Louis S, Pineau P, Amsellem-Ouazana D, Couraud PO, Strosberg AD,

Stoppa-Lyonnet D, Lidereau R, Nahmias C: Structural organization and expression of human MTUS1, a candidate 8p22 tumor suppressor gene encoding a family of angiotensin II AT2 receptor-interacting proteins, ATIP. Gene 2006, 380:127-136.

38. Di Benedetto M, Pineau P, Nouet S, Berhouet S, Seiz I, Louis S, Dejean A, Couraud PO, Strosberg AD, Stoppa-Lyonnet D, Nahmias C: Mutation analysis of the $8 p 22$ candidate tumor suppressor gene ATIP/MTUS1 in hepatocellular carcinoma. Mol Cell Endocrinol 2006, 252:207-215.

doi:10.1186/1471-2407-14-214

Cite this article as: Rogler et al.: Loss of MTUS1/ATIP expression is

associated with adverse outcome in advanced bladder carcinomas: data from a retrospective study. BMC Cancer 2014 14:214.

\section{Submit your next manuscript to BioMed Central and take full advantage of:}

- Convenient online submission

- Thorough peer review

- No space constraints or color figure charges

- Immediate publication on acceptance

- Inclusion in PubMed, CAS, Scopus and Google Scholar

- Research which is freely available for redistribution 